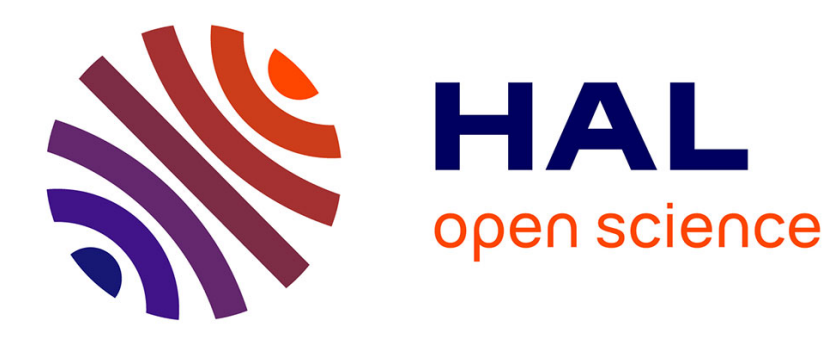

\title{
Thermal $\left(500-580{ }^{\circ} \mathrm{C}\right)$ stability of hydrogen in synthetic quartz
}

\author{
J. Bachheimer
}

\section{To cite this version:}

J. Bachheimer. Thermal $\left(500-580^{\circ} \mathrm{C}\right)$ stability of hydrogen in synthetic quartz. Journal de Physique IV Proceedings, 1994, 04 (C2), pp.C2-173-C2-176. 10.1051/jp4:1994220 · jpa-00252488

\section{HAL Id: jpa-00252488 https://hal.science/jpa-00252488}

Submitted on 1 Jan 1994

HAL is a multi-disciplinary open access archive for the deposit and dissemination of scientific research documents, whether they are published or not. The documents may come from teaching and research institutions in France or abroad, or from public or private research centers.
L'archive ouverte pluridisciplinaire HAL, est destinée au dépôt et à la diffusion de documents scientifiques de niveau recherche, publiés ou non, émanant des établissements d'enseignement et de recherche français ou étrangers, des laboratoires publics ou privés. 


\title{
Thermal $\left(500-580^{\circ} \mathrm{C}\right)$ stability of hydrogen in synthetic quartz
}

\section{J.P. BACHHEIMER}

Université Joseph Fourier, Laboratoire de Spectrométrie Physique, associé au CNRS, BP. 87, 38402 SaintMartin-d'Hères cedex, France

\begin{abstract}
Thermal stability of hydrogen as it appears in the $3125-3800 \mathrm{~cm}^{-1}$ infrared spectra has been studied as a function of the annealing temperature between $\sim 500$ to $580^{\circ} \mathrm{C}$ under vacuum or air atmosphere. Thin Z-cuts show a decrease of the $\mathrm{OH}$ infrared absorptions which can become clear above $\sim 520^{\circ} \mathrm{C}$ under vacuum. From these measurements we infere an increase of the diffusion coefficients for the $H$-outdiffusion in the range of about $10^{-11}$ to $10^{-10} \mathrm{~cm}^{2} / \mathrm{s}$ in vacuum from $\sim 520$ to $560^{\circ} \mathrm{C}\left(\sim 540\right.$ to $580^{\circ} \mathrm{C}$ in air $)$. $X$ and $Y$ cuts do not show outdiffusion for these temperatures.
\end{abstract}

\section{INTRODUCTION}

It is well-known that the performances of quartz $\left(\mathrm{SiO}_{2}\right)$ piezoelectric devices are limited by impurities [1] introduced during the hydrothermal growth. Among these, hydrogen $(\mathrm{OH}$ centers) has been shown to play a particularly important role because : i) it gives acoustic losses - related to a broad band water like infrared absorption - ii) it acts as a charge compensator, for the aluminium impurity, when the quartz is irradiated or when it is purified [2] using high temperature electrolysis ("sweeping"). The electrolysis are usually performed in a $500-550^{\circ} \mathrm{C}$ temperature range to avoid the $\alpha-\beta$ transition at $\sim 573^{\circ} \mathrm{C}$ which could induce electrical twins. It was shown [3] that it is possible to obtain, from vacuum electrolysis, synthetic quartz free of as-grown $\mathrm{OH}$ centers. Otherwise many authors $[4,5,6]$ have pointed out a modification of the infrared (I.R.)-OH spectra after prolonged time at high temperature. In particular a strong reduction of the "s" peaks (typical of the $\mathrm{OH}$ absorption in synthetic quartz) after annealing [5] or deuterium exchange [4] at $\sim 1000^{\circ}$ was put in evidence.

Here we present the results obtained from thin $X, Y$ and $Z$ cuts which were submitted to heat treatments under air or vacuum atmosphere with temperatures and durations typical of electrolysis processes. The $\mathrm{OH}$ content was monitored by the measurement of the infrared $\mathrm{OH}$ absorptions usually used to qualify the synthetic quartz: the sharp " $\mathrm{s}_{4}$ " band at $3584 \mathrm{~cm}^{-1}(2790 \mathrm{~nm})$ and the 3500 and $3410 \mathrm{~cm}^{-1}$ absorption coefficients to characterize the 
broad band (fig. 1). It has been shown [7] that a linear relationship exists between these coefficients obtained from as grown samples.

\section{EXPERIMENT}

All spectra were performed at room temperature using a Lambda 9 Perkin Elmer double beam spectrometer with an I.R beam (section $2 \times 4 \mathrm{~mm}^{2}$ ) which can be considered as practically polarized in the wavelenghts investigated $\left(3800-3125 \mathrm{~cm}^{-1}\right)$. To improve the accuracy, a virgin quartz was used as a standard to correct the spectrometer response.

Air annealing was made with an open air furnace. Vacuum was $\sim 2.10^{-6}$ mbar during the vacuum annealings.

\section{SAMPLES}

All the samples were cut in a small block of synthetic quartz of medium quality taken in the pure $\mathrm{Z}$ zone. They are square in shape with large faces optically polished. The dimensions are about :

$$
\begin{aligned}
& \text { - X cuts : } 0.75(/ / \mathrm{X}) \times 13.70(/ / \mathrm{Y}) \times 13.6(/ / \mathrm{Z}) \mathrm{mm}^{3} \\
& \text { - } Y \text { cuts : } 0.75(/ / \mathrm{Y}) \times 13.5(/ / \mathrm{Z}) \times 12.2(/ / \mathrm{X}) \mathrm{mm}^{3} \\
& \text { - Z cuts : } 0.85(/ / \mathrm{Z}) \times 10 \quad(/ / \mathrm{X}) \times 11 \quad(/ / \mathrm{Y}) \mathrm{mm}^{3}
\end{aligned}
$$

\section{RESULTS}

Fig. 2 and 3 show the evolutions of the absorption coefficients measured at the center of the samples. For the $Z$-cuts we give the mean of the $(\vec{E} / / X+\vec{E} / / Y) / 2$ absorption values from two samples. For the $X$-and $Y$-cuts we give the $\vec{E} / / Z$ absorptions which maximize the $\mathrm{s}_{4}$ intensity ( the $\overrightarrow{\mathrm{E}} \perp \mathrm{Z}$ absorptions practically show the same behavior but $\mathrm{S} 4$ is negligible ). $\mathrm{s}_{4}$ intensity is given both by its peak value and the area (dashed line) of the band. We see that the different annealings, made with comparable durations on the $X ; Y ; Z$-cuts, produce on the $Z$ - cuts a decrease of the absorption coefficients, at $\sim 520^{\circ} \mathrm{C}$ under vacuum (on fig. 2 top, the thickness $0.48 \mathrm{~mm}$ reported in addition shows a greater effect ) and slightly later under air ; on the $X$ and $Y$ cuts, practically no effect appears except for $s_{4}$ which peak absorption increases $[5,6]$ with however a nearly constant integral absorption.

Fig 4 shows the apparent diffusion coefficient $D$ calculated assuming that the rate of decrease of the $\mathrm{OH}$ absorptions ( $\mathrm{Z}$ cuts fig. 2 and 3 ) is governed by a one dimensional out diffusion process (verified at higher temperature: will be presented in a next paper) for hydrogen. Thus we used [see for instance 4] the formula :

$$
\frac{\vec{c}}{c o}=\frac{8}{\pi^{2}} \sum_{n=0}^{\infty} \frac{1}{(2 n+1)^{2}} e^{-\frac{(2 n+1)^{2} \pi^{2} D \cdot t}{L^{2}}} \quad \text { L : thickness of the sample }
$$

where we took the infrared absorptions ${ }^{*}$ as a measure of the mean $\mathrm{OH}$ concentration $\overrightarrow{\mathrm{c}}$ after the time $t$ of annealing. We find diffusion coefficients between $10^{-11} \mathrm{~cm}^{2} / \mathrm{s}$ and $10^{-10} \mathrm{~cm}^{2} / \mathrm{s}$ which are in reasonable agreement with extrapolated values obtained [8] from $\mathrm{H}-\mathrm{D}$ exchange at higher temperatures. A small temperature shift $\left(\sim 20^{\circ} \mathrm{C}\right)$ appears between

\footnotetext{
* We have substract $\alpha=0,021$ and $0,071 \mathrm{~cm}-1$ to account for the residual $\mathrm{SiO}_{2}$ intrinsec lattice absorption at 3500 and $3410 \mathrm{~cm}^{-1}$ respectively.
} 


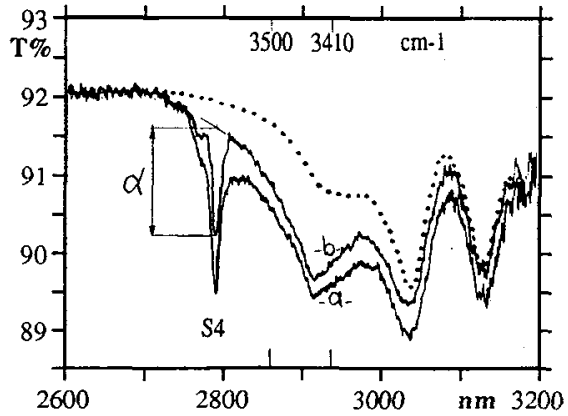

Fig. 1 : quartz I.R spectra with(_) and without(....) OH-absorptions . Example (Z-cut) of annealing effects: a: virgin; $b$ : after 21 days at $552^{\circ} \mathrm{C}$ under vacuum.
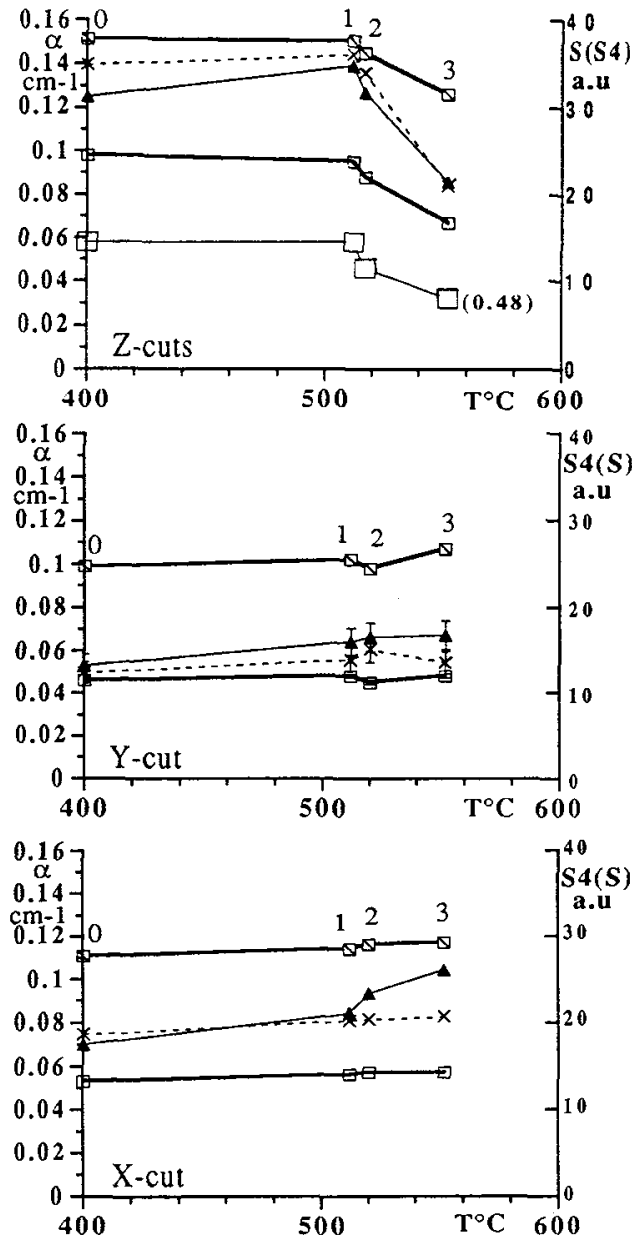

Fig. 2 : I.R. absorption coefficients vs the annealing temperatures (vacuum):

$\mathrm{S} 4$ : $\Delta$ peak, $\times$ area ; $\square 3500 \mathrm{~cm}^{-1} ; \nabla 3410 \mathrm{~cm}^{-1}$ $\underline{0}$ : virgin ; $\quad \underline{1}: 3$ hours at $445<\mathrm{T}<517^{\circ} \mathrm{C}$ $\underline{2}: 8$ days ; $\quad \underline{3}: 21(Z)$ or $26(X, Y)$ days

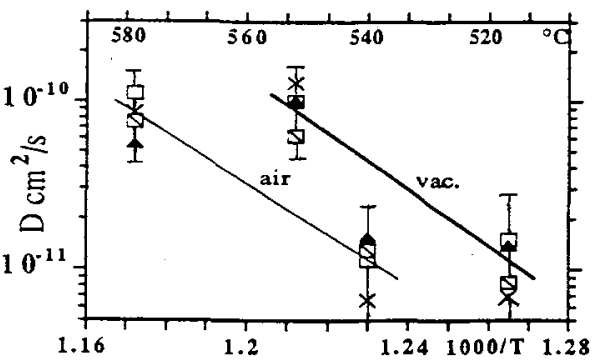

Fig 4 : Arrhénius plot (Z-cuts) of the H-outdiffusion coefficients calculated from :

S4 : A peak, $\times$ area ; $\square 3500 \mathrm{~cm}-1 ; \otimes 3410 \mathrm{~cm}-1$
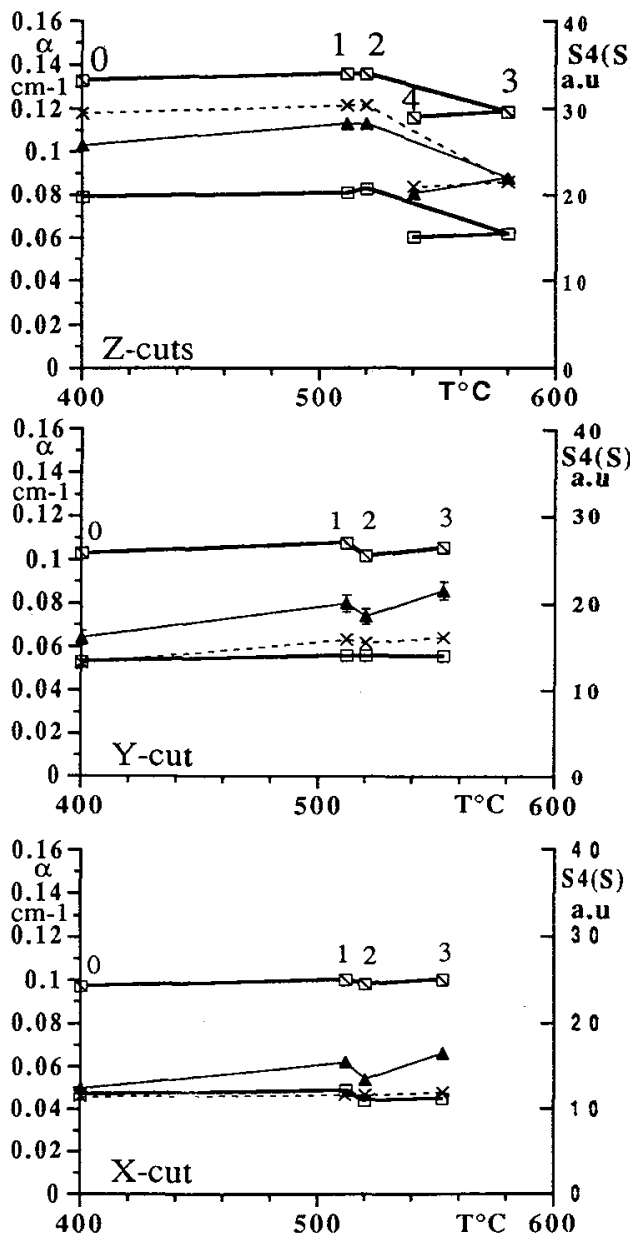

Fig. 3 : I.R. absorption coefficients vs the annealing temperatures (air):

$\mathrm{S} 4: \Delta$ peak, $\times$ area; $\square 3500 \mathrm{~cm}-1 ; \otimes 3410 \mathrm{~cm}-1$

$\underline{0}$ : virgin ; $\quad \underline{1}: 3$ hours at $445<\mathrm{T}<517^{\circ} \mathrm{C}$

$\underline{2}: 8$ days ; $\underline{3}: 16(Z)$ or $26(X, Y)$ days; $\underline{4}: 28$ days 
the values obtained from the air and vacuum experiments. Activation energies of $2.5 \pm 0.6$ $\mathrm{eV}$ is estimated, to be compared with the $1,6-2,1 \mathrm{eV}$ values found for the dc ionic conductivity attributed to $\mathrm{H}^{+}$displacement at the end of sweeping experiments $[2,3]$.

\section{CONCLUSION}

Annealing effects of medium quality synthetic quartz appear very anisotropic for the $\mathrm{OH}$ related I.R. adsorptions measured in the $3800-3125 \mathrm{~cm}^{-1}$ region. Thus we find a reduction of both the sharp $\mathrm{s}_{4}$ (integrated) band and the broad band above $\sim 520^{\circ}$ under vacuum atmosphere for the $Z$ cuts while no effect appears on the $X$-and $Y$-cuts except an increasing of the $\mathrm{s}_{4}$ peak absorption. Admitting that the $\mathrm{OH}$ reduction is governed by the hydrogen out ditfusion we find diffusion coefficient in rough accordance with the published data along the $\mathrm{Z}$ direction.

\section{ACKNOWLEDGEMENTS :}

The author thanks the SICN Company for supplying non standard quartz bar used in this investigation.

\section{REFERENCES}

[1] Brice J.C. , Review of Modern Physics 57 (1985) 105-146.

[2] Martin J.J. , IEEE Trans. Ultrason. Ferroelectr. Freq. Contr. 35 (1988) 288-296.

[3] Bachheimer J.P. and Dolino G. , 43 ${ }^{\text {rd }}$ Ann. Freq. control Symp. IEEE (1989) 517-520.

[4] Kats A. , Philips Res. reports 17 (1962) 133-279.

[5] Dodd D.M. and Fraser D.B. , J. Phys. Chem. solids 26 (1965) 673-686.

[6] Cordier P., Doukhan J.C., American Mineralogist, 76 (1991) 361-369.

[7] Charkraborty D. and Lehmann G. , J. of Solid State Chemis. 17 (1976) 305-311.

[8] Kronenberg A.K., Kirby S.H. , American Mineralogist 22 (1987) 739-747. 